\title{
A Case Report of Extensive Pyoderma Gangrenosum on the Upper Third of the Body
}

\author{
Hendra Gunawan (1D) \\ Retno Hesty Maharani (D) \\ Pati Aji Achdiat \\ Reti Hindritiani \\ Department of Dermatology and \\ Venereology, Faculty of Medicine, \\ Universitas Padjadjaran - Dr. Hasan \\ Sadikin General Hospital, Bandung, \\ Indonesia
}

\begin{abstract}
Pyoderma gangrenosum (PG) is a sterile inflammatory neutrophilic dermatosis that can present as a peristomal, pustular, bullous, vegetative, or ulcerative variant. It commonly affects the lower extremities, mainly in the pretibial area. We describe a case of extensive PG in an 18-year-old Indonesian man, involving the upper third of the body. Dermatological examination showed multiple painful ulcers with violaceous borders on the face, occipital region of scalp, neck, shoulder, upper chest, and back. The diagnosis of PG was established based on the histopathological examination that revealed massive dermal neutrophilic infiltration mixed with lymphocytic inflammatory infiltrates accompanied by leukocytoclastic vasculitis. The patient was treated with methylprednisolone equivalent to $1 \mathrm{mg} / \mathrm{kg} /$ day of prednisone. An excellent response to therapy also confirmed the diagnosis of PG. Since lesions of PG can appear on any part of the body, including the upper third of the body, a complete and appropriate examination is useful in establishing diagnosis.
\end{abstract}

Keywords: extensive, pyoderma gangrenosum, upper third of the body

\section{Introduction}

Pyoderma gangrenosum (PG) is a rare chronic inflammatory disease with an unknown etiology and characterized by neutrophilic infiltration of the skin. ${ }^{1,2}$ The term of PG was first introduced by Brunsting et al in $1930 .^{3}$ Based on the clinical manifestation, PG is classified into five subtypes: peristomal, pustular, bullous, vegetative, or classic (ulcerative). ${ }^{4,5}$ The lower extremity is the most common predilection site for PG. ${ }^{1,6}$ However, it can also occur on other sites of the body, including the trunk, upper extremities, head, and neck. ${ }^{7}$ Oral corticosteroids alone or in combination with other sparing agents such as azathioprine, cyclosporine, cyclophosphamide, mycophenolate mofetil, methotrexate, thalidomide, and dapsone were shown to be effective in most cases of PG. ${ }^{8}$ Here, we report a case of extensive PG on the upper third of the body in an 18-year-old man who was successfully treated with systemic corticosteroid alone.

\section{Case}

An 18-year-old Indonesian man presented with a 12-month history of multiple painful ulcers on the face, occipital region of scalp, neck, shoulder, upper chest, and back. The primary lesions were erythematous pustules on the right temple, gradually increased in size to form nodules that broke into painful ulcers. Two months later, the lesions extended progressively into multiple ulcers with a band-like pattern to the right eyelid, right-side of the forehead, cheeks, occipital region of the scalp, neck, shoulder, upper 

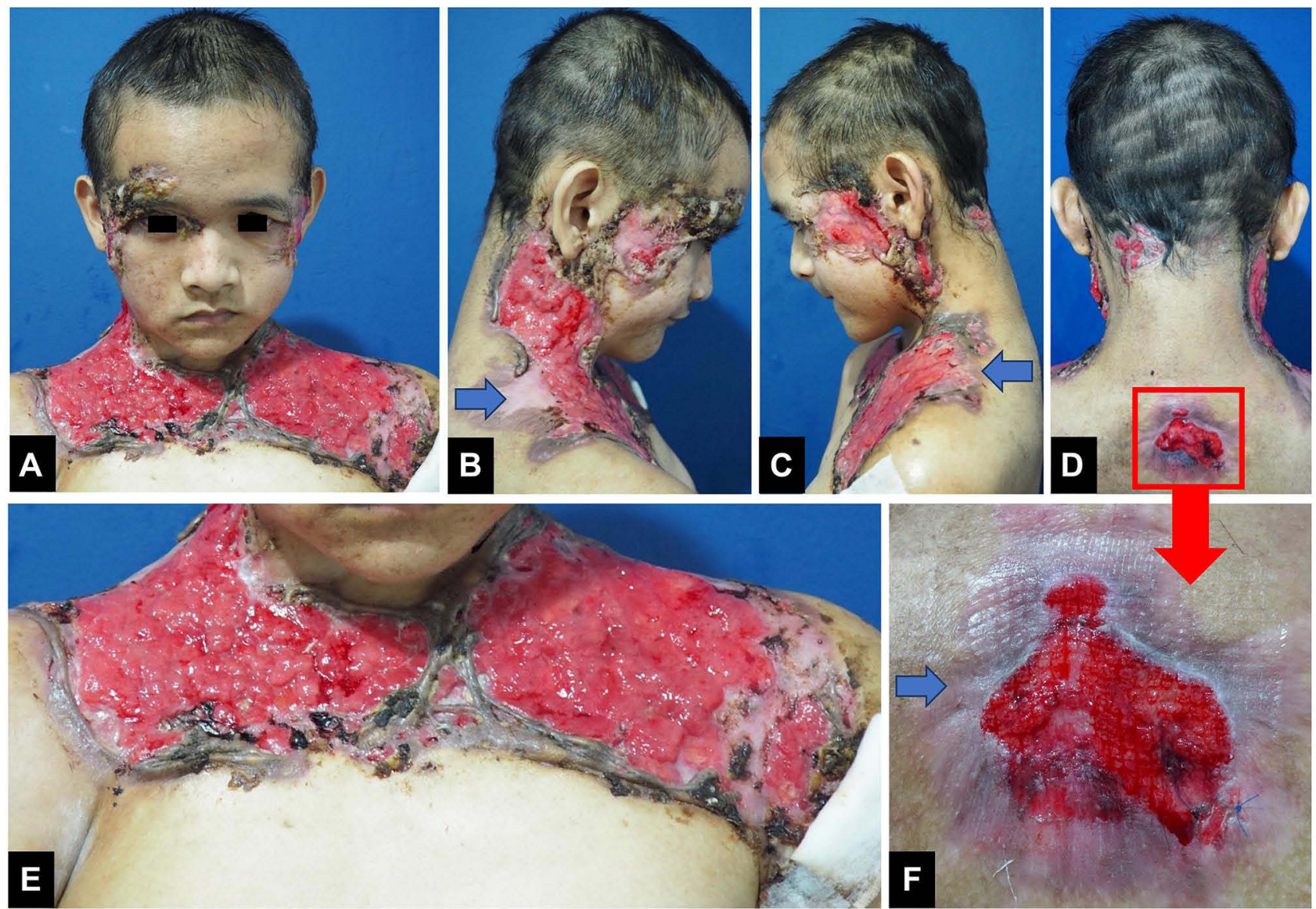

Figure I (A-F) Multiple ulcers with granulation tissue on the face, occipital region of the scalp, neck, shoulder, upper chest, and back. (B, C, D and F) A violaceous border appeared around the ulcers (blue arrow). (F) is the enlargement of the region marked with a red square region in (D).

chest, and back. The margins were violaceous and partly covered with yellow adherent crusts. The patient experienced weight loss but had no history of trauma, inflammatory bowel disease, or arthritis. History of chronic cough or hemoptysis, intermittent fever, night sweats, lumps in the neck, armpits, groins, and contact with patients with chronic cough were absent. There was no history of alcoholic beverage consumption, narcotics, psychotropic substances, addictive substances use, tattoos, or sexual intercourse. Physical examination showed extra-ocular pseudoptosis. Multiple ulcers with granulation tissue at the base of the wound were found on the face, occipital region of the scalp, neck, shoulder, upper chest, and back (Figure 1A-F), with violaceous borders around the ulcers (Figure 1B, C, $\mathrm{D}$ and F). Gram staining, Ziehl-Neelsen staining, and potassium hydroxide tests using microscopic examination did not reveal any fungi or bacteria. Human immunodeficiency virus (HIV) examination was nonreactive, with a cluster of differentiation (CD) 4 cells were 794 cells $/ \mu \mathrm{L}, \mathrm{CD} 8579$ cells $/ \mu \mathrm{L}$, and CD4:CD8 ratio of 1.37. Chest $\mathrm{x}$-ray result was within normal limits. Pathergy tests in post-biopsy wounds and culture of bacterial and fungal isolates taken from the ulcer were negative. Histopathological examination from the edge of the ulcer showed skin ulceration (Figure 2A), massive dermal neutrophilic infiltration mixed with lymphocytic inflammatory infiltrates (Figure 2B), accompanied by leukocytoclastic vasculitis (Figure 2C), with no evidence of infection or malignancy. These histopathological findings supported the diagnosis of PG. The patient received methylprednisolone equivalent to $1 \mathrm{mg} / \mathrm{kg} /$ day of prednisone, tapered off every 2 weeks. Ulcer size reduction with cribriform atrophic scars indicated significant improvement, and no new skin lesions appeared after 5 months of observation (Figure 3A-F). The patient's good response to the therapy also confirmed the diagnosis of $\mathrm{PG}$.

\section{Discussion}

Pyoderma gangrenosum is a rare neutrophilic dermatosis. ${ }^{2,9}$ The incidence is estimated at around 3-10 cases per million population per year. ${ }^{5,6}$ Initial PG lesions can be in the form 

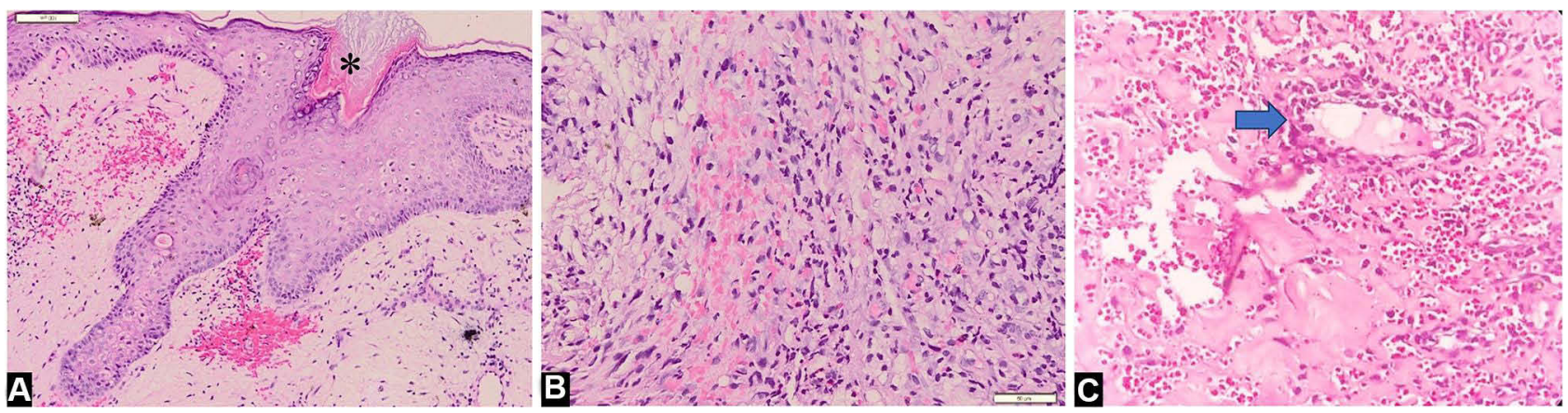

Figure 2 Biopsy specimen from the edge of the ulceration (Hematoxylin and eosin, $x 10$ and $x 20$ magnifications). (A) Histopathological findings showed skin ulceration (asterisk). (B) Massive dermal neutrophilic infiltration mixed with lymphocytic inflammatory infiltrate. (C) Leukocytoclastic vasculitis (blue arrow).
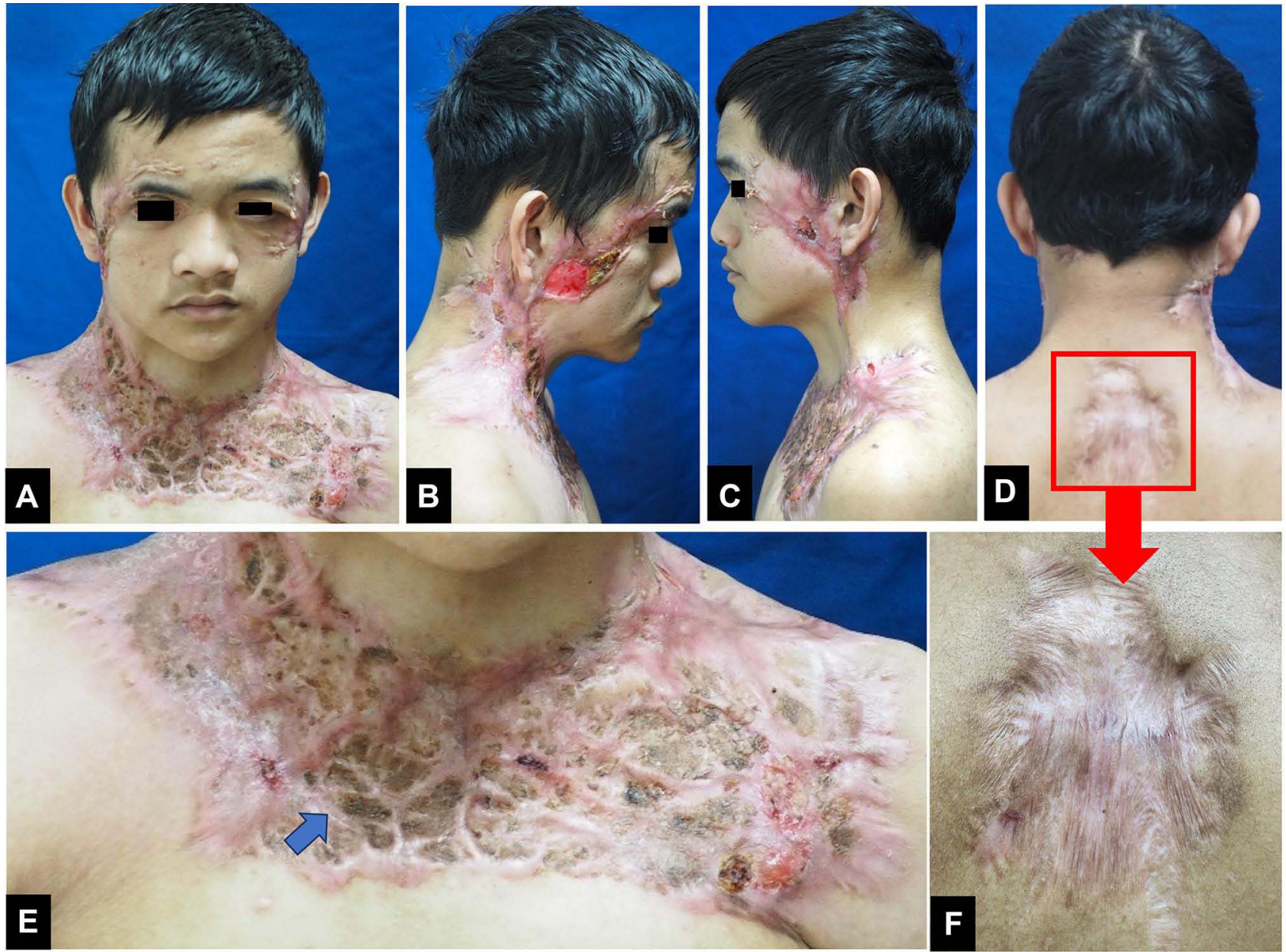

Figure 3 (A-F) After 5 months, cribriform atrophic scars developed at the sites of the previous lesions (blue arrow). (F) is the enlargement of the region marked with a red square in (D).

painful pustules, nodules, or plaques. ${ }^{1,2}$ Within a few days, the skin lesions may enlarge and rupture to form well-defined ulcers, with irregular violaceous edges. ${ }^{9,10}$ The skin and subcutaneous tissue subsequently become necrotic, with a brittle wound bed covered in hemorrhagic or purulent exudative fluid. The ulcers are accompanied by increased severity of pain. ${ }^{9}$ Re-epithelialization occurs from the ulcer edge, leaving the cribriform atrophic scars. ${ }^{411}$ PG lesions are generally multiple and recurrent and occur in traumatized areas in $25-50 \%$ of the cases, known as the pathergy phenomenon. ${ }^{4,9}$ Based on one of the largest case series of PG, $77.7 \%$ of the lesions appeared on the leg, followed by the 
trunk (11.7\%), peristomal site, and the upper extremities $\left(8.7 \%\right.$ each), the head and neck $(7.8 \%) .^{7}$ Pereira et al ${ }^{12}$ found that the most common patients had a single lesion (62.5\%), while multiple (more than three) lesions occurred only in $16.7 \%$ of the cases. Approximately $50 \%$ of the PG cases are accompanied by systemic diseases such as inflammatory bowel disease, arthritis, solid malignancies, hematological malignancies, HIV, and rheumatological disorders. ${ }^{5,13,14}$ In this report, the patient had initial lesions in the form of pustules that enlarged into nodules, then ruptured to became tender ulcers with uneven edges. We observed hemorrhagic crusts covering the granulation tissue at the base of the wound on the right-side of the forehead, temples, cheeks, occipital region of the scalp, neck, shoulder, upper chest, and back. Violaceous borders were seen around the lesions, in addition to the hypertrophic scars in the facial area. The clinical manifestations of the ulcers were characteristic of PG lesions. The patient's pathergy sign was negative, and there was no history of symptoms of systemic diseases associated with PG. To the best of our knowledge, extensive PG in multiple sites, mainly on the upper third of the body as in our case, constitutes an unusual case of PG.

Based on the Mayo criteria, diagnosis of PG is established if two major and two minor criteria were fulfilled. ${ }^{4}$ The major criteria include 1) rapid progression of painful necrotic ulcer, with irregular, violaceous, and undermined edges, 2) elimination of other etiologies of skin ulcers. The minor criteria include 1) history of pathergy or clinical finding of cribriform scarring, 2) PG-related systemic disease, 3) appropriate histopathology finding, and 4) rapid response to systemic corticosteroid administration. ${ }^{4,9,11}$ In this case report, the patient met both major criteria and three of the minor criteria, namely the presence of cribriform scars, histopathological finding concordance to PG, and good response to systemic corticosteroid therapy alone. Diagnoses of bacterial and fungal infections were excluded from microscopic and histopathological examinations and also cultures.

To date, there is no gold standard treatment for $\mathrm{PG}^{9}$ Therapeutic recommendations are generally based on successful studies of PG patient management. ${ }^{1}$ Ideal therapy of PG includes wound care (dressings), topical, and/or systemic treatment. ${ }^{9}$ Prednisone $1-2 \mathrm{mg} / \mathrm{kg} /$ day or methylprednisolone up to $0.8 \mathrm{mg} / \mathrm{kg} /$ day remains the first-line therapy in most PG cases. Systemic corticosteroids are generally given until clinical improvement occurs. Subsequent doses are gradually reduced to prevent recurrences. ${ }^{1,9}$ In this case, the patient initially received an injection of $7.5 \mathrm{mg}$ dexamethasone once a day (equivalent to prednisone $1 \mathrm{mg} / \mathrm{kg} /$ day) for a week, followed by $32 \mathrm{mg}$ methylprednisolone orally per day for 2 weeks, tapered-off every 2 weeks.

On the 28th day of treatment, ulcers on the upper back region began to heal, becoming atrophic scars. Furthermore, the ulcers had significant clinical improvement after 5 months of therapy, as the ulcer size decreased, cribriform atrophic scars formed, and no new skin lesions appeared.

\section{Conclusion}

Chronic ulcers can be caused by a variety of etiologies. This includes PG, a rare inflammatory disease, which is sometimes difficult to diagnose. PG can occur at any area of the body, including the upper third area. Complete and appropriate examination of clinical features, laboratory, and histological findings, with good response of therapy, is useful to establish the diagnosis.

\section{Ethics Statement}

The publications of images were included in the patient's consent for publication of the case. Institutional approval has been obtained to publish the case details.

\section{Consent Statement}

The authors certify that they have obtained all appropriate patient consent forms. The patient signed a consent form for the publication of the case details and images.

\section{Acknowledgments}

The authors would like to thank the staff of the Department of Dermatology and Venereology, Faculty of Medicine, Universitas Padjadjaran, Bandung, West Java, Indonesia.

\section{Funding}

There is no funding to report.

\section{Disclosure}

The authors report no conflicts of interest in this work.

\section{References}

1. Jourabchi N, Lazarus G. Pyoderma gangrenosum. In: Kang S, Amagai M, Bruckner AL, et al., editors. Fitzpatrick's Dermatology. 9th ed. Vol. 1. New York: McGraw-Hill; 2019:605-616.

2. Dessinioti C, Katsambas AD. Pyoderma gangrenosum. In: Katsambas AD, Lotti TM, Dessinioti C, D'Erme AM, editors. European Handbook of Dermatological Treatments. New York: Springer; 2015:827-833.

3. Brunsting LA, Goeckerman WH, O'Leary PA. Pyoderma (echtyhma) gangrenosum - clinical and experimental observations in five cases occuring in adults. Arch Dermatol Syphilol. 1930;22(4):655-680. doi:10.1001/archderm.1930.01440160053009 
4. Skopis M, Bag-Ozbek A. Pyoderma gangrenosum: a review of updates in diagnosis, pathophysiology, and management. J Multidsicip Res. 2021;4:367-375.

5. Alonso-Leon T, Hernández-Ramírez HH, Fonte-Avalos V, ToussaintCaire S, Vega-Memije ME, Lozano-Platonoff A. The great imitator with no diagnostic test: pyoderma gangrenosum. Int Wound J. 2020;17:1774-1782.

6. Aziret M, Kara Ș, Yaldiz M, Kőse N, Aşikuzunoğlu F, Cevrioğlu AS. An extensive pyoderma gangrenosum mimicking necrotizing fasciitis: an unusual case report. Int J Surg Case Rep. 2021;81:105697.

7. Saigal R, Singh Y, Mittal M, Kansal A, Maharia HR. Pyoderma gangrenosum. J Assoc Physicians India. 2010;58:378-383.

8. Ahronowitz I, Harp J, Shinkai K. Etiology and management of pyoderma gangrenosum: a comprehensive review. Am J Clin Dermatol. 2012;13:191-211.

9. Wollina U. Pyoderma gangrenosum - a review. Orphanet J Rare Dis. 2007;2:1750-1772.
10. Davis MD, Moschella SL. Neutrophilic dermatoses. In: Bolognia JL, Schaffer JV, Cerroni L, editors. Dermatology. Philadelphia: Elsevier; 2018:453-471.

11. Binus AM, Qureshi AA, Li VW, Winterfield LS. Pyoderma gangrenosum: a retrospective review of patient characteristics, comorbidities and therapy in 103 patients. Br J Dermatol. 2011;165(6):12441250. doi:10.1111/j.1365-2133.2011.10565.X

12. Pereira N, Brites MM, Gonçalo M, Tellechea Ó, Figueiredo A. Pyoderma gangrenosum - a review of 24 cases observed over 10 years. Int J Dermatol. 2013;52(8):938-945.

13. Ruocco E, Sangiuliano S, Gravina AG, Miranda A, Nicoletti G. Pyoderma gangrenosum: an updated review. J Eur Acad Dermatol Venereol. 2009;23:1008-1017.

14. Chateau A, Makhubele J, Dlova N. Corticosteroid wraps as monotherapy in a child with extensive idiopathic pyoderma gangrenosum. Pediatr Dermatol. 2021;38(1):184-186.

\section{Publish your work in this journal}

Clinical, Cosmetic and Investigational Dermatology is an international, peer-reviewed, open access, online journal that focuses on the latest clinical and experimental research in all aspects of skin disease and cosmetic interventions. This journal is indexed on CAS.
The manuscript management system is completely online and includes a very quick and fair peer-review system, which is all easy to use. Visit http://www.dovepress.com/testimonials.php to read real quotes from published authors. 